\title{
Constrained by Managerialism: Caring as Participation in the Voluntary Social Services
}

Apetheker (1989) argues that people resist in the ways they have open to them and the tactics and storylines available in often constricted contexts. Focusing on the voluntary social services sector, this article suggests that workplace participation operates in the same way - - strategies and tactics used in workplace participation reflect people's perceptions of the possibilities available to them in any given context or regime and their calculations of constraints and risks. In general, workplace participation in the public and private sectors is thought to be based on a combination of self-and collective interests (Marchington, 1992). In the voluntary social services sector, participation also draws strongly on notions of care, which involves a values-based, emotionally laden form of other-directed interests. Though workplace participation in the form of militant unionism is often associated with maleness and generally begins and ends in the workplace itself, participation in the form of values and affinity are associated with naturalized caring roles for women and leak out of the workplace to the larger community and home life (Author A, 2006). In the voluntary sector, care is a highly gendered and contested terrain in which the workforce and service users demand greater participation in all aspects of care provision (Van Til, 2001; Weeks, 1994).

Participation in the predominantly female voluntary social services is assumed the norm that most workers expect, but little is known about how participation plays out in the circumscribed realities of managerialism and outsourcing. This article asserts that three kinds of overlapping participative processes exist in the voluntary social services including: 1) procedural-formal; 2) practice-professional; and 3) affinity- processes that 
intersect with the gender-associated notions of caring and its connection to social mission and values. Our data suggests that rather than expanding in the context of third way politics, opportunities for all three kinds of participation have been severely curtailed by managerialism. As well documented in the literature, many workers and managers in the nonprofit sector resent the ways that managerialism has increasingly stripped away possibilities for participation in the workplace and have developed direct and indirect ways to resist the loss of these opportunities and build new participatory processes (Aronson and Smith, 2009; Author A, 2009; Author B, 2008).

This article presents arguments drawn from two international comparative case studies of changing working conditions in 'best practice' voluntary agencies (one in each of Scotland and Australia) where caring was found to be a form of workplace and social participation, providing deep meaning and interconnection between workers, clients and communities, as well as simultaneously supplying the basis for exploitation and abuse of the workers by employers and clients. Though the two agencies converged in terms of managerialism, they diverged in terms of the practice-professional models they embraced and the role 'care' played in the services they delivered. In both cases, caring was a concept and set of practices for which workers struggled and sacrificed, as well as an interactive process that energized workers and helped them resist managerialism. However, in the Australian example, this took place surreptitiously as care was replaced with more functional aspects of support.

The article will start with a brief summary of the research project from which the data in this article is derived. The article then turns to a discussion of the multiple contexts of work in the contemporary voluntary services sector. We present a three-part 
analytic frame for examining forms of participation in the voluntary sector and use the findings from the two case studies to highlight these processes. Further discussion and conclusions follow.

\section{The Study}

Though this article draws only data from Australia and Scotland, the data were collected for a larger, multi-site, multi-country exploration of the changing conditions of work life in the voluntary sector. Study sites in Australia and Scotland were selected using a criterion method (Strauss \& Corbin, 1998), seeking service providers widely regarded as 'best practice' agencies. Both agencies provided multiple services on- and off-site to people fully- or partially exclusion from mainstream services including education, housing, health care and so forth. Data collection involved in-depth, semi-structured interviews, participant observations and a review of agency documents. A total of thirty three interviews were conducted - - twelve in Australia and nineteen in Scotland. Interviews involved: three front-line supervisors ( 2 in Scotland +1 in Australia), seventeen front-line staff (10 in Scotland +7 in Australia), two senior Human Resource specialists $(1+1)$, one Health and Safety Manager (in Scotland), two trade union representatives $(1+1)$ and two senior directors (Australia) and four senior heads of service in Scotland. Interviews were tape recorded, lasted between forty-five minutes to two hours, and were transcribed verbatim.

Three participant observations also took place in each agency. Due to volatile conditions, the observations in Scotland were necessarily shorter, involving walkthroughs, informal participation in services, and discussions with service users and 
providers who happened to be present. In Australia, more traditional, multi-hour observations could take place with the observer embedded in the service setting. Observations were naturalistic, involving a mixture of interaction and informal discussions with agency workers and service users (DeWalt, 2002). Observations were selected through a process in which key informants were asked to suggest sites that might provide valuable data. Field notes were taken, and written up as soon as possible after the fact. Data were analysed using NVIVO8 and drew on grounded theory (Glaser \& Strauss, 1967). Reflecting the critical framework for this study, data analysis explored interconnections between concepts, surface realities, hidden realities and existing knowledge (Madison, 2005).

\section{The Multiple Contexts of Work in the Voluntary Sector}

Providing care to a number of under serviced populations, the voluntary sector services walk a tightrope between the rights of service users and providers (Hughes et al., 2005; Priestly et al., 2007). Originally, the nonprofit sector was thought to provide a response to market and government failure, providing services only where public provision ended and encouraging collective engagement on community problems (Brock and Banting, 2002; Bush, 1992). Beginning in the 1980s, public services were downloaded to the voluntary and for-profit sector through a number of mechanisms including outsourcing and competitive tendering.

New Public Management, Gendered Work and Workplace Participation Though the putative intent of outsourcing was to make services more democratic, participatory and responsive to the needs of communities, evidence suggests that neither 
service users nor employees have seen much improvement (Author B, 2009; Richmond and Shields, 2004). For workers, shifts from public to voluntary sector provision saw the introduction of cost cutting measures and efficiencies that eroded their capacity to speak for and with the communities they served (Van Til, 2000). Demands for accountability and inadequate resources placed pressure on nonprofit agencies to adopt mangerialist approaches, such as New Public Management (NPM) (Evans and Shields, 2002, 1998). Claiming to coach employees in 'best practices', managerial models script and quantify performance in order to cut costs and reduce waste (Smith, 2007; Clarke and Newman, 1997). Given the difficulty associated with measuring the precise outcomes of collective forums for decision making and employee discretion, NPM provided the justification for removing or reducing participative practices long associated with nonprofit work (Author A, 2009a, 2004a; Author B, 2008). These practices included: staff meetings, trainings, workshops, peer supervision, community development, coalition work, activism, and social change initiatives.

Highly circumscribed work practices have triggered many workers to seek other opportunities to participate in the decisions that shape their capacities to provide care for individuals and communities. Evidence from Canada shows voluntary sector workers turning increasingly to social unionism, using collective bargaining as vehicles for increased 'voice' in workplace decision-making and organizing their union locals as bases for widespread social activism and community building (Author, 2002a, 2009b). Workers in Australia are appear more likely to undertaken activism outside their workplaces and filter their concerns through existing advocacy and policy organisations such as Peak Bodies (Author, 2009b). 
Most who work in the predominantly female voluntary social services sector do so because of their commitment to provide care for a certain population (for example, people with disabilities, youth, homeless people), to social caring in general, social justice or all three (Author A, 2009a; Nickson et al., 2007). Whether highly professionalized or performed by unpaid family members, care has been a highly gendered undertaking in which caring about (emotional tasks) is generally combined with caring for (physical tasks) (Smith, 20007; Baines et al., 1998; Weeks, 1994). Some place female participation in the voluntary social services at $80 \%$ (Anglicare, 2006); others place it closer to $75 \%$ (Saunders, 2004). Rather than skill- and knowledge-based, care work tends to be seen as something women do naturally, making it difficult to command higher wages and benefits (Aronson and Smith, 2009). Dovetailing with presumed female attributes such as the endless capacity to care, the literature confirms that selfexploitation and sacrifice are essential to the viability of a sector in which funds have always been in short supply and the lines between paid and unpaid work blurred (Author A, 2006; Author B, 2008).

Bettina Apetheker (1989) argues that for women, resistance has often focused on ongoing, incremental change, concentrated on sustenance, dignity and interconnectivity, echoing themes found in the home, rather than sudden, dramatic events in the streets. We suggest that participation in the voluntary social services works the same way. The highly feminized workforce finds notions and tactics of care and altruism compatible with their gender roles and personal values; hence it provides a justification for involvement in workplace resistance and a rationalization to press for greater work place participation. 
Service User Rights, Small Business Solutions and the Decline in Care Workers' Rights Gaining momentum in the 1980s and 90s, service users' rights movements challenged the notion of 'care' (Watson et al., 2004). Pointing to its controlling and infantilizing aspects, disability rights activists, in particular, demanded full citizenship rights and control over all aspects of decision making and the services provided to them (Hughes et al., 2004). While recognition of these rights is well overdue, these demands coincided with the introduction of outsourcing and welfare state retrenchment (Ungerson and Yeandle, 2007; Ungerson, 1999), turning the struggle for clients' rights into a zero sum game of inadequate resources and private market-like managerial models in which workers lose out when service users gain and vice-versa; one groups' gain tends to encroach on another's entitlements (Author et al., 2009b; Torjman, 1996).

Reflecting the overall dominance of the marketplace as the solutions for social problems, service users' rights movements have increasingly demanded that governments provide individualized budgets and voucher systems in which the service user generally assumes responsibility for hiring, firing and supervising their own staff (Priestly et al., 2007; Ungerson and Yeandle, 2007). Like other small businesses, most service users have little knowledge of, or capacity to comply with, basic employment standards or health and safety legislation. Low wages, few, if any, benefits, pensions or vacation days, coerced unpaid overtime and highly flexible shifts (especially split shifts and very short shifts at any time of the day or night), has eroded workers rights in this sector (Author A et al., 2009b; Leece, 2008).

Some agency-based care continues to exist alongside voucher care. Within agency-based care, the rights of workers rights have often been placed in direct conflict with the rights of service users through the increasing use of Person-Centred Care models 
(PCC). Purported to be strength-based and solution-focused, PCC can be lauded for its progressive ideals about service users' rights. Within PCC, workers are instructed to facilitate and nurture the independence (rather than dependence or interdependence) of service users and foster 'functionality' through the provision of 'just enough supports', rather than all-encompassing care. PCC also views violence and other forms of 'acting out' behavior as efforts to communicate, requiring interpretation and decoding on the part of service providers rather than rebuke or redirection (Joseph Rowntree, 2006). In contrast to earlier less formalized models of care, PCC is a leaner, more efficient provision. Consistent with NPM imperatives, it can be described as a targeted and more sustainable solution to the growing demands for care. However, as the Australian case will show, PCC can also be used to marginalise, if not deny, staff rights.

\section{Care and Emotional Connection}

Care remains widely accepted and central to the ethos in the voluntary sector even though it is eschewed by much of the disability rights' movement. Caring pivots on feminized notions of deep, though often short-term, emotional connection, mutual giving (in ways appropriate to the capacities of each) and, even, love for clients (Fine, 2004; Author A \& B). Emotional interconnection means participating in the lives of others. In the context of nonprofit social services, some clients and communities need help in order to participate - the kinds of claims they make are not readily "heard" by mainstream society - - hence, participation in the voluntary sector often focuses on building the communication skills and capacities of others as well as advocacy for and with marginalized populations (Smith, 2007). Workers, managers and directors also use the concept of emotional connection with service users (caring about) in order to justify their own participation in 
agency-level and larger decisions. Indeed many workers seem unwilling to advocate for themselves unless it is cloaked within the legitimacy of care for others (Author A).

Not underestimating its power and impact, Clarke (2004) notes the 'uneven and unfinished character" of the neoliberal project (27), as well as the ways that more democratic forces such as 'the public' ${ }^{\mathrm{i}}$ continue to disrupt its smooth functioning (44). He sees evidence of the unfinished nature of this project in instances of 'recalcitrance, resistance, obstruction and incomplete rule' (44). Though criss-crossed with tensions, gendered notions of caring and self-exploitation seem to provide a base for resistance and expanded participation within the increasingly managerialised (neoliberalised) voluntary social services workplace. As the findings will show, this participation includes both social and labour process aspects, and as such, has the potential to unite community and workplace struggles.

\section{Analytic Frame}

Foley and Polyani (2006) note that workplace participation occurs when employees are allowed input into organisational decisions, 'even if it means they only suggest ways to implement decisions that have already been made'(174). In contrast, workplace democracy is thought to exist when employees have real control over organizational goalsettling and strategic planning, ensuring that workers' goals can be met, rather than just those of the organization (174). In the nonprofit sector the distinction between democracy and participation is not so clear cut. Like many other workplaces, participation can be 'formal or informal, direct or indirect; it may cover one, some, or all areas of decision-making (Schuller, 1985: 4)'. It is the relationship between these forms 
of participation that is 'crucial, rather than the absolute degree' (Schuller, 1985: 9). The values workers bring to the voluntary sector predispose them to seek greater control of power and resources in order to empower their clients. Some of this struggle takes place in the workplace, and some beyond, with or without the support of trade unions.

Consistent with a more egalitarian ethos, most voluntary agencies have adopted decision making structures that operate somewhere along the continuum from consultative to collective-consensus participation. These models reflect different constructions of social care, the needs of individuals and communities and solutions to larger questions of social justice and equity. The majority of voluntary agencies operate within a variation of the consultative model, where management seeks input from staff on policy directions and strategies, though final decisions rest with management who may choose to adopt or ignore staff suggestions. A small minority of voluntary organizations operate as consensus-based, collectives where all staff participates in all decisions pertaining to the agency, staff, service delivery, social advocacy and activism(Weeks, 1994).

For the purposes of this article, we have developed a three-part frame to analyse workplace participation in the voluntary sector. 1) Procedural-formal processes are aimed at fostering or omitting staff participation in discussing and influencing organizational goals, processes, policies, planning and priorities. In classic terms, this form of workplace participation might be referred to as direct and indirect participation in planning, development and organizational goal setting. Participative forums such as joint decision making committees or agency-wide planning councils are included in this category as are unionization and collective bargaining. With the exception of union 
activities, these participatory processes exist at the discretion of management, making them vulnerable to reduction or removal.

2) Practice-professional processes draw on knowledge developed in front-line practice or within professional theory, and funnel this knowledge into the ways staff understand and under take their everyday work. In classic terms, this form of workplace participation might be referred to as autonomy and discretion in key aspects of work organization. Professional and quasi-professional worksites place a high value on direct worker control over the intensity of work, task content, duration of care, and so forth. Workers' discretion draws on formal knowledge including post-secondary education and training (professional), as well as tacit knowledge gained on the job from other workers and workplace experience (practice). In most workplaces, staff members are consulted extensively on models of practice though ultimate decision making rests with management. Freezing workers out of this kind of decision is not unknown, while a minority of agencies cede all decision making in this area to their staff.

3) Affinity processes involves direct and indirect non-commercial ties between service users, co-workers and communities and the interpretive screens used to understand these ties and the actions associated with them as care. While they range from relatively passive to very engaged and active, affinity processes often provide the rationale or impetus for workers to demand greater participation in the workplace, whether it be for their own issues and those of others. The division between the issues of workers and the issues of the communities and individuals they serve is rarely clear cut, often muddied by shared concerns and agendas of care and social change. Gendered notions of altruism and affinity (that is, practices that work in tandem with norms regarding women's presumed 
natural capacity to connect emotionally with others and provide a range of support services) are also relevant as they compel workers to express care by demanding and creating expanded opportunities for themselves and their clients to participate at multiple levels of society, including voluntary agencies and the services they provide. As will become evident, attempts to strip the work of social interconnectedness and shared responsibility for problem solving, so as to recast the work as a set of technical interventions, has not been well received by some of the Australian women workers dicussed below.

\section{Findings}

\section{Case Study One - Australia}

Australia's welfare state bears striking similarities to the British system and in most analytic schemes, finds itself placed in the same liberal welfare state category, providing various social entitlements within a framework of enhancing and promoting the private market (Lightman, 2003; Esping-Andersen, 1998). The agency studied in Australia was very similar to agencies providing the same kinds of services in the UK, except for one striking difference. Drawing on a model developed in the United States, the agency consciously distanced itself from the notion of care or affinitive participatory processes, claiming instead to provide 'just enough supports' and 'the right kinds of supports' to enable people to live independent lives, replete with full community ties, commitments and involvement. Through a carefully scripted process referred to as 'Technologies of Support', workers were coached to avoid building caring ties or relationships with service users and co-workers (that is, avoid affinitive participatory processes), restricting 
themselves to meeting the physical tending required by service users, facilitating opportunities for the service users to participate in the community and build relationships with non-employees whom they encountered in the wider community. In effect, the role of the worker was a silent back drop to the goal of service users leading full lives within the larger community with emotion-based, interpersonal connections within the agency itself minimized. Effectively, the worker was stripped of his or her own personality, autonomy and needs for social connection (affinity); and remade as a physical body existing in the workplace to do only those things that management deemed appropriate for service users' growth and self determination. While management expected workers to have a 'positive regard' for clients and colleagues, care and emotional ties were to be actively avoided. Within this technical notion of support, workers' commitment to social justice was not deemed necessary and pre-existing skills in this area were not considered desirable

This Australian model intervened at the level of practice-professional and affinitive processes, reshaping the kinds of work people undertook, how they did it, and the interpretive screens they were encouraged to embrace. Through training and coaching workers were told to understand Technologies of Support as a cutting-edge, highly skilled, knowledge-driven, rights-based, compassionate service delivery model. The model also suggested appropriate emotional states for the workers to assume, which in this case was emotional absence or neutrality which can also be understood as an absence of affinity, recasting care work as ignoble, inferior and harmful while simultaneously scripting caring feelings and actions out of the work content and the larger ethos of the workplace. Though the agency was regarded as a 'best practices' 
agency, its derogatory construction of 'care'(affinitive processes) placed it outside the larger discourse of the voluntary sector where caring is valorized, contributing to a sense of mutual good will among workers and the communities they serve.

Representing changes in the procedural-formal processes for participation, training assumed a pivotal role in ensuring that staff understood the tight parameters of their role. Drawing on his background in industrial engineering, the HR Director coined the phrase 'Technologies of Support' to highlight the agency's focus on the impersonal and mechanistic aspects of support work. Here he comments on the role of training in meeting these goals:

what we do in our base training for our staff is we try and ensure that we do not have staff come to work and support someone in the way they would care for their own family or their own children. They come to work and use a set of technologies and a set of skills that we've educated them in to provide a technical function called support.

Stripped of emotional connection and sociability, the HR Director felt that 'support' could easily be taylorised, though not necessarily to save money, instead with the aim to improve the quality of the services. As he put it, 'I can see it very much in terms of time and motion... a change in the ratio between inputs and outputs.'

Resisting the encroachment on affinitive participation as well as the narrowed practice-professional processes that had been put in place, most workers in the agency voiced skepticism or open opposition to the new model. When asked about some of the closely scripted aspects of the Technologies of Support model, one long time worker said:

I don't like these rigid plans and strategies - when we have a problem we need to draw on our experience and the immediate situation and think on our feet. Every situation is slightly different or completely new and one size does not fit all. 
These plans just hamstring you, make you less effective, and harm the clients. They (the clients) need us to know them and know what works and make changes as we go along. You can't write all that stuff down. By the time you've developed a strategy, the situation has changed.

Another senior worker agreed, noting:

We used to call it individualized intervention plans or something. Now it has a new name and we have to write it out and get it approved and it's just the same old thing. Mostly you need to use the knowledge you get from working with these guys every day. You have to have a real connection with people and through trial and error work out what works for them and for you. It's pretty straight forward.

When asked if she had participated in the development of the new policies (procedural-formal processes for participation), practice models (professional-practice processes) or other aspects of the agency another worker argued that the CEO and managers used to draw on the expertise of the front-line staff when setting policies and agency goals, but they were no longer interested in hearing from staff. According to the worker, staff meetings and trainings focused only on non-participatory processes such as 'indoctrinating' workers in the new approach. A number of staff expressed concern that training sessions rarely involved an exchange of ideas or opportunities to identify emerging problems and solve them (professional-practice processes). Instead training focused almost exclusively on drilling people in the new model. Highlighting the importance of affinity processes of participation and ways that she resisted the new 'supports model', one staff member argued:

You gotta care about these guys or you wouldn't do the work. I provide care for these guys (the clients) and some of the care is supports and some is doing it for them when they need it, and most of it is about really connecting with them and knowing them. (SNORTS) Caring, support - whatever, I just do the job.

Echoing the words of his CEO, the HR Director saw care relationships as 'paternalistic, controlling and infantilizing' and discouraged them at every level of the 
agency. Though he pointed out that research confirms that service users want and seek affirming relationships with care providers, he argued that, when service users in the agency try to build affinity with those providing their care,

Hopefully we would move the person to a place where they wouldn't even seek or need that relationship with us. We've gotta support people in having relationships, but those relationships aren't with us.

Providing an example of the degree to which he is willing to intervene when workers are not seen to be adhering to the new model, the Director of HR claimed he had moved staff people to new units and jobs when they seemed to be getting 'emotionally attached' to service users (circumventing affinitive processes). The HR Director was also skeptical of the need for friendships or affinity between and among staff members. Pointing out that opportunities for staff interaction were limited because most staff worked alone or with only one or two others, he argued that employees should get their workplace satisfaction from providing the right amount and kinds of taylorised support to clients rather than seek satisfaction in or support from friendships with fellow employees .

To meet their training goals, the agency had a newly appointed Practice Coach whose background was fast food management. When asked if the fast food training was helpful in the social services sector, she replied

It was great - really practical, no theory stuff that doesn't work - just stuff that really works with people and (the name of the fast food outlet). I've used it a lot over the years.

The Practice Coach claimed that she never hired people based on their training, experience in the field or credentials as this generally required too much in the way of 'unlearning' caring approaches (unlearning affinitive and professional-practice processes). Instead, she was developing a hiring process, in conjunction with the HR 
Director, to screen job applicants for the appropriate values. So far they had hired 'a chef, a baker's wife, a salesperson, and a stay-at-home wife'. Notably, she had not hired anyone with a background or training in social services. As she put it:

If you find the right values, you find the right person. Non-traditional people are usually the best. I never look for training or experience. It's values that count.

Another senior worker, one of the few with professional credentials, noted that while the CEO claimed to be hiring people based on values, maybe he was just trying to save money by not hiring people with experience or education. This concern was echoed by other workers, including the union steward who also noted that the internal training failed to meet national standards and consequently did not move anyone up the pay scale or give them a broader picture of social services. When she asked the CEO about this, she was told that the agency did not 'want to train people up for them to move into a different organisation' as it was 'a waste of money'. Instead people were provided with unique, non-credentialed, non-transferrable skills.

A mid-level worker also wondered if providing supports rather than more fulsome care (affinity processes) was partially motivated by cost savings. Noting that providing 'just enough supports' rations the number of services offered to clients, she argued:

I think if you do (the work) properly you're not going to create dependence anyway. I'm sometimes cynical...I think it's the powers that be worrying about money. I think that's my gut instinct. It's not so much about building dependence at all.

Another senior worker worried that the highly technical training did not appeal to most people seeking employment in this field training and contributed to the agency's very high turnover rate:

Every time they hire a bunch of new staff, the staff only stay a short time and leave. I can't figure it out. They all seem really nice and seem to do really good, 
but after their training is over they seem to just quit. I don't know if they are too young or too inexperienced or just don't like the work but they don't stay.

Both these quotes represent resistance to the curtailment of affinity and professionalpractice participatory processes. In one case the worker challenges the discourse of care as patronizing and dependence building, wondering if the new model is prompted by cost saving. In the other, newly hired staff failed to attach to the job and leave the job.

In addition to inculcating staff in the agency's Technologies of Support model, the Practice Coach was also leaving her old job as supervisor of a special needs unit. The unit was seen by the upper echelons of the agency as its showpiece, demonstrating what the agency's model could do and where they hoped to be heading. The service user, Mitchell (not his real name), had previously been institutionalized at considerable cost and the state government provided financial incentives to the agency to provide 'supports' for him in the community, despite his very challenging behaviors. Despite her strong verbal commitment to the 'Technologies of Support' model, during a participant observation at the showplace unit, the Practice Coach was observed to interact with the Mitchell in a very informal way that included addressing him by an infantilizing nickname (Mitchy-Moo), inviting him to come give her 'some sugar' (a kiss? a hug?) when she first arrived and continuing to speaking in strongly affectionate terms about him and openly contradicting the supports philosophy and practice:

God love him. He's such a lovely man. I know we're supposed to support people and not care for them but you gotta love him. All the staff love him, we all just love him.

The staff person on duty joined the conversation, noting that though they work closely with the service user, the staff are not his family, nor should they be; they are professionals. He asserted that the service user should have his own family and friends 
and staff should not try to replace that. Though this testimony places tight parameters on affinity processes and adheres closely to the Technologies of Support model contradictions quickly emerged. The practice coach drew the researcher's attention to birthday cards, sent recently to the service user and signed by staff with phrases such as 'hugs from Barb', 'love always', 'way to go, we are so proud of you' and 'to our darling Mitchell'. Strongly emotive, these messages cross the line between technical, impersonal support and affection. A similar observation was made when the researcher was invited to look at photos from a Christmas party with all staff present at a dinner prepared by the service user and his mother. Rather than displaying minimal, technical supports and the prohibition on building relationships, the staff seemed to be exhibiting close, family-like relationships and 'going the extra mile' on a day usually reserved for close relatives. The researcher wondered aloud about staff attendance at the dinner on Christmas day despite the family demands they must have on their time. The Practice Coach replied, 'well, after Mitchell and his mother went to all that work, what else could we do? We all had such a good time.'

Underscoring the ways that procedural-formal processes had changed across the larger agency, most of the staff who participated in this study expressed frustration that few avenues were available through which to voice their concerns. They also claimed that those who raised concerns were not well treated by management. For example, though our researcher saw broken picture frames and holes in the wall at the showplace unit, read about injuries in their staff log, and observed Mitchell repeatedly striking himself, hitting his head on the wall, and attempting to pinch one staff member, the following exchange with the Practice Coach confirmed the workers' claims above: 
Researcher: Violence and back injuries are supposed to be the biggest problem in this sector. Are these problems at (the unit)?

Coach: Sometimes, when Mitchell isn't travelling well, we have a few problems but if staff are using the plans and just enough supports there is no reason for anyone to get hurt.

Researcher: What if someone got hurt?

Coach: I'd ask them what they were doing and how they could do it better next time.

Researcher: Do you think people report their injuries or would they be worried about being questioned or blamed for the problem?

Coach: People can write anything in the log book and most do every shift, but there's not much there about injuries (note: there were many entries about injuries). If people are using the right approach, there is no reason for anyone to get hurt.

The same sentiment was expressed by the CEO who informed us that violence should theoretically decrease in units where the technical supports were properly implemented. If violence occurred, it was because the workers were doing something wrong and he would want to know what. Blaming workers for problems in the workplace, particularly violence in which they have been victimized, casts a chill over staff attempts to participate in decision making or offer feedback, representing an absence of opportunities for participative processes at the level of procedural-formal or professional-practice.

\section{Australian Case Study Analysis}

Though starting from the laudable premise that marginalized populations deserve more opportunities to exercise personal agency, the data show that the model used in this agency shut down most workplace participative processes and attempted to shut down caring (affinity). The data also show that the agency was not particularly successful at 
the latter, though it experienced some success at the former. Even the Practice Coach quickly reverted to expressions of caring and strong affinity once she found herself back on the front-lines interacting with clients, and unashamedly drew the researcher's attention to cards and photos documenting activities replete with emotion and compassionate-connectedness.

On the other hand, the agency had been quite successful at removing opportunities for staff to participate in decision making, planning, setting goals (procedural-formal) and work organization (professional-practice). Rather than trusting the skills and practice knowledge of their staff (professional-practice), the coaching and training involved in the Technologies of Support attempted to reduce workers' autonomy to physical tending. Most forums for joint decision making (procedural-formal) had been removed in a series of cost cutting moves and the training and staff meetings that continued to exist appeared to be used as opportunities to single-mindedly promote the 'support model', rather than to problem solve, trouble shoot or envision better policies and practices (professional-practice).

Though perhaps unintended, this model parallels many of the achievements of managerialism and incorporates many of its aspects. Tightly scripted intervention plans removed unwanted emotion and connection (affinity) in the agency we studied, but it also reduced purported waste and error, contributing to cost saving and accountability. Given their belief that caring relationships with clients were not desirable, flexible workforces worked just as well or better than permanent ones (procedural-formal and professionalpractice) because constantly changing part-time and contract staff does not have the time 
to develop close connections with those they 'support' (affinitive processes). Flexible staffing has the additional benefit of contributing to cost saving.

\section{Case Study Two - Scotland}

The agency we studied in Scotland was recommended as a best practices agency in which conditions of work and service provision met a higher standard. Our data show that workers were attracted to the agency because of this reputation and the way it melded with their own commitment to care for others. Though procedural-formal and professional-practice participatory processes existed, affinitive processes were the most evident and influential, culturing workers to accept difficult conditions and to press for more and better ways to deliver care. Our data also show management making conscious efforts to evoke and sustain a caring culture by encouraging staff to identify with the agency mission and the populations it served. Workers frequently expressed deep caring and love for their clients and enjoyed the relative autonomy they experienced within the model of Person-Centred Care (PCC) used by the agency.

As noted earlier, within PCC, care is based on the needs of the service user, rather than institutional routines and priorities. Staff appreciated this non-standardized approach to care work, reporting that every day could be different or "no two days are the same'. In this scenario, PCC provided a way for staff to set their tasks and the order of these tasks according to the perceived needs of the client, rather than the explicit instructions of the employer. This gave them a participatory role in work organization or professional-practice content, as well as providing legitimation of their participation in 
this level of decision making. Staff enjoyed the consistency between PCC and the value they placed on affinity processes or caring, interdependency and interactivity.

Similar to other organizations in the Scottish voluntary sector and reflecting a form of affinitive participation, the agency had adopted a policy of 'non-exclusion' for service users which included working with client groups with which local authorities and other providers were unable to cope. Staff strongly supported the non-exclusion policy and felt that their influence in all the forums available to them had ensured its adoption. A senior manager argued that non-exclusion was one of the agency's core values:

We have never been the sort of organization that gives up on people, it's about sticking with them.

Non-exclusion policies also had the effect of shifting the service user population to hardto-serve client groups. No longer willing to provide public services for many high needs individuals, Local Authorities in Scotland often provided higher funding to voluntary agencies willing to take on their care, in effect creating incentives for agencies to develop specialty niches in hard-to-serve populations. The best practice agency we studied had a large population of various kinds of service users who had been excluded from most or all other services and exhibited very challenging (usually violent and/or abusive) behaviors.

The twinning of PCC, and the agency's non-exclusion policies set up a strong tension between the service user's right to care and workers' rights to work in an environment free of violence. Most employees adopted the PPC-based/affinity-based notion that violence and acting out were forms of communication, rather than anti-social behavior, and these behaviors should be decoded and interpreted by workers in order to more helpfully address the concerns of service users. Managers noted that the policy of 
non-exclusion meant that sometimes, employees had to accept the threat- or acts of violence and tried to assist employees in coping with these pressures:

You are asking them (the staff) to do a really difficult job where they may face violence and abuse from people we support, but at the same time taking the employee and trying to provide them with the support they need to tolerate that.

Management took efforts to socialize employees into the workplace ethos of tolerance and deep caring in order to assist them in dealing with hard-to-serve populations. In other words, management undertook deliberate strategies to nurture affinity processes of participation. Socialization techniques pivoted on the recruitment of appropriate personnel and persuading/encouraging them to accept a fair degree of violence in their working lives. The first stage in this process was recruitment; the 'right people' for the jobs were caring, skilled and hard working. Representing an overlap of two participatory processes, through the procedural-formal process of recruitment, potential staff members were granted the opportunity to participate in the workplace and larger community by taking on the task of caring for and about people (affinity) whom most others have abandoned or neglected.

The second stage of building affinity processes was robust training and induction, clarifying to the nature of the work and preparing staff to conduct themselves safely and competently. A senior manager observed:

The recruitment processes are pretty rigorous and about trying to do good assessments on where people are with their values and their understanding of the nature of the job and what we are asking them to do, so that they are not too shocked when they start. Its difficult treading that balance between attracting people positively, and being totally honest about what you are really asking them to do. (Emphasis added)

Unfortunately, tight resources meant that there were gaps in these processes. Staff claimed that induction and training were not uniformly available. For example, at a 
residence for highly excluded children, teachers and front-line support workers reported that they had little or no awareness of the exact environment in which they were hired to work in, coupled with little or no job description, and no one to job shadow or act as mentors. For the most part, they had to learn on the job with few supports or guidance.

A further example of formal procedures aimed at fostering staff's capacity to care despite difficult working conditions, staff were encouraged to turn to their supervisors for debriefing and support after violent incidents but as management confirmed, supervisors were not always available. Supervisors experienced very heavy workloads, in large part due their preoccupation with mechanisms associated with managerialism and outsourcing such as external regulatory, financial and operational documentation requirements. One long time staff person noted that supervision was the lowest she had experienced during her many years in the sector. A front-line manager confirmed this:

Opportunities for reflection, discussion and absorbing these issues are very difficult to achieve in services that have huge funding constraints, or its lone working you know. There is nobody there if you have to manage a difficult situation. There is maybe some young female worker who has gone through a really difficult shift with some very challenging client with learning disabilities and she knows there is no intentional violence, but that doesn't make it any easier when she is going off shift, not feeling great and not having someone to chat that through with.

Caring/affinity was put to the test in the face of abuse from clients. Verbal abuse was an everyday occurrence in many of the projects attached to the larger agency. Verbal comments usually focused on an employee's vulnerabilities such as build, weight or sexual orientation. One long term employee noted:

The number of times I get verbal abuse in a day is amazing. An example would normally be you know, 'you fat b.......' 
Abuse could be aimed at whoever was in ear shot or targeted at a particular member of staff for a sustained period of time. A young support worker told us the following:

There was one boy who was here for a while and I was to do one-to-one with him, he was about 13, and he targeted me right from the very beginning. It was target, target, target. And there were two occasions where I just sat in a room and sat down and was crying because I just couldn't take this constant bombardment...it was verbal, but now and again you would get physical, not punching you but pushing you. So there were times when I was just so down I was just so exhausted.

Physical violence was also a frequent occurrence. Among the fourteen front-line staff we interviewed, half reported that they had experienced physical assault in the last year.

Two individuals had been involved in separate incidents in the ten days prior to our study. Front-line managers also reported experiencing verbal abuse and assault from service users, one within the last week.

Not unlike survivors of wife assault who excuse and normalize violence in the home (Fraser, 2008; Baines, Evans and Neysmith, 1998), workers maintained their affinity to service users as well as their commitment to professional-practice forms of participation by normalizing and excusing the violence, as 'part of the job' or refusing to see themselves as victims. As exemplified in the story below, workers found ways to feel that the service users did not intend to hurt them and, in fact, returned the affinity workers felt for them,

The few incidents that I've been involved with that have become violent have not been aimed at me, and I think that is the difference. I think if I had been deliberately assaulted by one of the boys then I would find that a lot different, but I don't feel that I have ever been deliberately assaulted. I put myself into a situation to try to protect somebody and got a punch, which I think is an entirely different thing than somebody lashing out at me.

Again, similar to those who experience wife abuse (Fraser, 2008; Author A), research participants expressed feelings of deep compassion for service users despite the violence. 
There were limits to affinitive connections and commitment to the professionalpractice model as seen in the staffs' attempts to cope with workplace violence. Some workers used strategies such as absenteeism, gallows humor, and sudden resignations to cope with the stress and injury. The workplace was also unionised, with a density of around $30 \%$ and had experienced a strike in the year preceding our study. Interview data revealed deep dissatisfaction with the degree of effort and stress employees were expected to take on for limited financial rewards. Despite this workers participated in the strike with great trepidation over what would happen to the clients, revealing their strong affinity for those they served.

Work actions, such as strikes, are a form of procedural-formal participation. Though workers must step outside of the immediate parameters of the agency in order to participate in strikes and work action. Those who do so with an eye to improving service and caring for the larger community, act in a way that is consistent with the notion of affinity and the social justice values that drew them to the sector (Author A, 2009). Much of the social union activism emerging around the world pivots on the notion that defending workers' rights to provide high quality service is a form of struggle worthy of the support of the entire community.

Like other voluntary agencies, the Scottish agency had a diminished capacity to provide procedural-formal opportunities for participation. Also similar to other nonprofit organizations, collective forums for policy debate and reflecting on organizational priorities were less frequent in the agency studied than they had in the past. The content of the debates was often more restricted too. New service development seemed to be an exception to this norm as some of the workers we interviewed had been actively involved 
in a community needs assessment process that recommended the innovative new service in which they were now employed. Other examples of consultation and participation seemed to indicate that the agency still embraced the ethos of staff and client involvement in decision making though tight resources made it difficult to enact. A number of staff at various levels of the agency noted that they were consulted regularly by their supervisors on questions of service delivery and felt they could use the infrequent collective forums, such as staff meetings, group supervision sessions and trainings, to voice concerns, clear the air, and suggest changes. These measures represent examples of all three kinds of participative processes - - formal procedures continue to exist for consultation and voice, practice-professional insights are solicited for new programme development and feedback on existing services, and affinity is encouraged through a variety of measures that validate caring and the provision of services with a caring connection.

\section{Discussion and Conclusion}

As evident from this study, people participate in organizations and resist prevailing regimes in many ways, based in part of their sense of what opportunities are available to them and their sense of the constraints, risks and social obligations. The data from both Scottish and Australian research participants illustrate how multi-layered and contextual worker acts of resistance and participation can be. The data also shed light on how staff members participate in organizations, including organizations that may shun, let alone welcome, their involvement. This article suggests that in the context of the voluntary social services, care, resistance and participation are linked. All involve engagement, 
agency and a search for meaningful ways to work with colleagues and service users. Our data show that in everyday practice, all three participative processes frequently interweave, influencing though not constituting one another. Our data also suggest that in the context of managerialism and third way politics, possibilities for all three kinds of participation have been devalued, reduced or removed.

\section{1) Procedural-formal mechanisms of participation}

With the exception of union action, opportunities for procedural-formal participation seemed to be the most vulnerable to managerial restructuring. Staff in both agencies reported a decrease in opportunities and forums for input and decision making including staff meetings, group supervision, and training aimed at problem solving and trouble shooting, rather than indoctrination. Opportunities for workplace democracy and participation exist in voluntary social service agencies at the discretion of management and as our data show, they can easily be reduced or removed to cut costs or deflect unwanted staff criticism. Union actions were noted at both agencies - - in the form of strike action in the Scottish agency and in the case of concerns about the lack of nationally recognized training in the Australian agency. In both cases, workers used their collective voice to demonstrate their dissatisfaction with the care environment, though reflective of the erosion of union strength under neoliberalism, little change was observed in either case, with the consequence that workers resorted to more individual forms of resistance.

\section{2) Practice-professional forms of participation}


In the Scottish agency, workers had been involved in setting key pieces of policy such as non-exclusion and expressed satisfaction in the relative autonomy they were provided to set and order tasks within PPC, a model that was broadly consistent with their values and priorities. In Australia, the workers felt they had been frozen out of decision making and that their care knowledge was denigrated and marginalised within the Technologies of Support model. However, both agencies promoted service users' rights, often to the detriment of staff rights and opportunities to participate. In the Scottish case, the focus on service users' rights produced outcomes that fostered care and interconnections between staff and service users, while the same focus encouraged the depersonalization of staff in the case of Australia. Despite the difference in intended outcomes, the workers in both agencies persisted in relationships that encouraged interconnection between staff and clients, laying the base for workers' knowledge and experience to be brought back into work organization, even if it had to be done without managements' explicit knowledge.

\section{3) Affinity based participation processes}

Affinity or basic humanistic care processes seem to be the most resilient and near omnipresent form of participation in this sector. These micro-participative processes operated in a myriad of ways and spaces despite the restrictive environment provided by managerialism. At its best, affinity is a form of participation exemplifying the notion that people are interconnected, have an inherent interdependence, and that they should work together to advance the interests of themselves and others. Affinity differs from the positive regard workers may perform in other kinds of service work, in that it involves 
non-commercial connections to service users and communities, motivated by a sense of social obligation and shared pursuit of a greater cause such as social justice. As a gendered undertaking, affinity reflects and reinforces the gendered division of care found in the larger society, underscoring the feminist claim that rather than a stark division between home and work life, many aspects of social life operate in distinctly similar ways with similar rewards, dilemmas and relations (Krull and Sempruch, 2009; Baines, Evans and Neysmith, 1998).

Unfortunately, the Scottish data shows that affinity processes often overshadowed the rights of the predominantly female work force, jettisoning them into situations where they were expected to sacrifice their safety and well being for the service users. Those who resisted, for example through strike action, did so with great reluctance and concern for their clients. This dynamic bears an unfortunate similarity to chronic wife abuse where violence is excused and normalized in ways not dissimilar to those we documented in the workplace experience of Scottish care workers.

\section{Summary}

The data in this study show that care is a connective process, underlying and motivating participation and as a force that compels involvement in the lives of others, care is at least a micro-participative process. Care or affinity not only persisted in the face of opposition, but it was also used by workers as a counter discourse and set of practices with which to resist the erosion of worker participation and open up less autonomized practices and ways of connecting with fellow staff, clients and the communities they served. The data suggest that while managerialism and taylorised practice models may remove or reduce 
opportunities for worker participation, care is a theme or storyline that gave workers other ways to understand their work and why they did it, as well as ways they were prepared to resist managerial priorities and directives, including the erosion of various kinds of direct and indirect participation. The degree of resistance possible, even in the highly technocratic worksite in Australia, shows that cracks and fissures exist within managerialism. Clarke (2004) might see this as an example of how neoliberalism repeatedly encounters noncapitulation among those working within or recognizing the benefits of the larger notion of the social as a site of mutual responsibility and care. The data show that the notion of caring provided workers with an enduring entry point from which to nurture, legitimize and expand their resistance and opportunities for participation.

Though promising, a cautionary note is necessary as care is no magic cure.

Rather, it is part of a contradictory and contested set of social relations. Reflecting the vulnerability of affection and interdependence, care provides deep meaning and interconnectivity between workers, clients and larger communities and smoothes the way to further participation, however it also provides an axis on which exploitation and abuse of the largely female work force is tolerated and largely ignored.

\section{Endnote}

${ }^{1}$ Clarke (2004) sees the public as a number of overlapping social phenonmenon including: the public interest, public services meeting the needs of the public and the public as a collective body capable of having interests and needs.

\section{References}

Anglicare (2006) Anglicare Victoria Workforce Review. Melbourne, Australia: Anglicare Victoria's Social Policy and Research Unit. 
Aronson, J. and Smith, K. (2009) 'Managing Restructured Social Services: Expanding the Social?' British Journal of Social Work. Advance Access, January 7.

Aptheker, B. (1989). Tapestries of life. Women's work, women's consciousness, and the meaning of daily experience. Amherst: University of Massachusetts Press.

Author A

Author B

Author C

Baines, C., P. Evans, and S.Neysmith. (1998) Women=s Caring. Feminist Perspectives on Social Welfare. Toronto: Oxford Press.

Brock, K. and Banting, K. (2001) 'The Nonprofit Sector and Government in a New Century: An Introduction'. In Brock, K. and Banting, K. (eds.) The Nonprofit Sector and Government in a New Century. (pp. 1-20) Montreal and Kingston: McGill-Queens University Press.

Clarke, J. (2002) Dissolving the Public Realm? The Logics and Limits of Neo -liberalism. Journal of Social Policy. 33 (1): 27-48.

Clarke, J. and J. Newman. (1997) The Managerial State. London: Sage.

DeWalt, K. (2007) Participant Observation: A Guide for Fieldworkers. Walnut Creek, CA: AltaMira Press.

Esping-Andersen, G. (1998) Social Foundations of Postindustrial Economics. London: Oxford.

Evans, B. and Shields, J. (2002). The third sector: Neo-liberal restructuring, governance and the re-making of state-civil society relationships. In The Handbook of Canadian Public Administration. C. Dunn (ed.) Toronto: Oxford University Press.

Evans, B. \& Shields, J. (1998). Reinventing' the third sector: Alternative service delivery, partnerships and the new public administration of the Canadian post-welfare state. Working Paper \# 9. Toronto: Centre for Voluntary Sector Studies, Ryerson University.

Foley, J. and Polyani, M. (2004) 'Workplace Democracy: Why Bother? Economic and Industrial Democracy. 27(1): 173-191.

Fraser, H. (2008) In the Name of Love. Women's Narratives of Love and Abuse. Toronto: 
Women's Press.

Glaser B.G. and A. L. Strauss. (1967) The Discovery of Grounded Theory. Strategies for Qualitative Research. Chicago: Aldine Publishing Company.

Greenfield, W. (2004). 'Decision Making and Employee Engagement', Employment Relations Today 31, 2: 13-24.

Hughes, B., McKie, L., Hopkins, D., \& Watson, N. (2005). Love`s labours lost: Feminism, the disabled people's movement and an ethic of care. Sociology, 39(2), 259-275.

Joseph Rowntree Foundation. (2006) Promoting Person-Centred Care at the Front Line. York, UK: Joseph Rowntree Foundation.

Krull, C. and Sempruch, J. (2009) Demystifying the Family/Work Contradiction: Challenges and Possibilities. Vancouver: UBC Press.

Leece, J. (2008) 'Paying the Piper and Calling the Tune: Power and the Direct Payment Relationship', British Journal of Social Work. 1-19.

Levitas, R. (2005) The Inclusive Society? Social Exclusion and New Labour. Basingstoke: Palgrave Macmillan.

Lightman, E. (2003). Social Policy in Canada. Toronto: Oxford University Press

Madison, D. (2005) Critical Ethnography: Methods, Ethics and Performance. Newbury Park, CA: Sage.

Morris, J. (2001) 'Impairment and Disability: Constructing an Ethics of Care That Promotes Human Rights' in Hypatia, Vol. 16, No. 4, Fall, pp1-17

Nickson, D., Warhust, C., Dutton, E. and Hurrell, S. (2008) 'A Job to Believe In: Recruitment in the Scottish Voluntary Sector', Human Resource Management Journal. 18, 1: 20-35.

Priestley, M., Jolly, D., Pearson, C., Riddell, S., Barnes, C. and Mercer, G. (2007) 'Direct payments and disabled people in the UK: supply, demand and devolution', British Journal of Social Work. October (37): 1189-1204.

Richmond, T. and Shields, J. (2004). NGO restructuring: Constraints and consequences. Canadian Review of Social Policy. 53 (Spring/Summer), 53-67.

Salamon, L. (1993) 'The Marketization of Welfare: Changing Nonprofit and for Profit Roles in the American Welfare State', Social Service Review, March, 1-39. 
Saunders, R (2004) Human Resource Issues in Canada's Non-profit Sector - A Synthesis Paper. Ottawa: Canadian Centre for Policy Alternatives.

Schuller, T. (1985) Democracy at Work. Oxford: Oxford University Press.

Smith, K. (2007) Social work, restructuring and resistance: 'Best practices' gone underground. In D. Baines (ed.) Doing Anti-Oppressive Practice. Building Transformative, Politicized Social Work. Halifax: Fernwood Books.

Strauss A. and Corbin C. (1998) Basics of Qualitative Research: Techniques and Procedures for Developing Grounded Theory. Thousand Oaks (California): Sage Publications.

Torjman, S. (1996) Dollars for Services: a.k.a. Individualized Funding. Ottawa: Caledon Institute of Social Policy.

Ungerson, C. (1999) 'Personal Assistants and Disabled People: An Examination of a Hybrid Form of Work and Care', Work, Employment and Society. 12(4): 583-600.

Ungerson, C. and S. Yeandle (2007) Cash for Care in Developed Welfare States. New York: Palgrave.

Van Til, J. (2000) Growing Civil Society: From Nonprofit Sector to Third Space. Bloomington: Indiana University Press.

Watson, N., McKie, L., Hughes, B., Hopkins, D., and Gregory, S. (2004) (Inter)dependence, needs and care: The potential for disability and feminist theorists to develop an emancipatory model',. Sociology, 38(2), 331-350.

Weeks, W. (1994) Women Working Together. Lessons from Feminist Women's Services. Melbourne: Longman Cheshire. 